\title{
Adult onset ornithine transcarbamylase deficiency: an unusual cause of semantic disorders
}

\author{
S Rimbaux, C Hommet, D Perrier, J P Cottier, A Legras, F Labarthe, L Lemarcis, A Autret, F Maillot
}

J Neurol Neurosurg Psychiatry 2004;75:1073-1075. doi: 10.1136/jnnp.2003.026542

Ornithine transcarbamylase deficiency (OTCD) is the most common urea cycle disorder. This condition usually presents in neonates or children. This report describes the clinical case of a 21 year old woman who was diagnosed in adulthood during the course of an unexplained coma. After recovery from the coma, she presented very unusual neuropsychological disorders involving memory and the meaning of certain words, suggesting a semantic deficit. The discovery of OTCD in adulthood is rare and the neuropsychological consequences may be unique.

O rnithine transcarbamylase deficiency (OTCD) is the most common urea cycle disorder. ${ }^{1}$ This condition is mostly identified in neonates or children, and rarely in adults. There are few data on the neurological and cognitive outcomes of patients with adult onset OTCD. We describe the case of 21 year old woman with a particular neuropsychological clinical picture after a severe form of OTCD related hyperammonaemia.

\section{CASE REPORT}

A 21 year old woman was hospitalised in July 1999 for a rapidly progressive coma. Her only relevant past medical history was an episode of sleepiness associated with mental confusion, hypotonia, dysarthria, ataxia, and vomiting at the age of 12. The clinical signs rapidly resolved and food poisoning was suspected.

A few days before admission, the patient became unusually tired, disoriented, and had inappropriate speech. She was diagnosed with acute delirium and was hospitalised in a psychiatric institution. Her neurological status deteriorated rapidly, with the appearance of a hypotonic coma and bilaterally dilated pupils. A computerised tomography scan showed major brain swelling. Hyperammonaemia $(510 \mu \mathrm{mol} /$ litre; normal range, 14-38) and respiratory alkalosis led us to suspect a urea cycle disorder and OTCD was first confirmed by plasma amino acid profile and urinary orotic acid excretion $(350 \mu \mathrm{mol} / \mathrm{mmol}$ creatinine; normal value, $<5)$, and later by DNA analysis. ${ }^{2}$ While the coma was subsiding under specific treatment, she presented a clinical picture of massive anterograde and retrograde amnaesia, a language disorder characterised by word loss, reading and writing difficulties, and apathetic behaviour. Brain magnetic resonance imaging showed extensive bilateral anterior temporal atrophy and high signal intensity in the cortex (uncus, insular and cingular cortex regions) (fig 1). A perfusion scan (SPECT HMPAO) demonstrated severe frontal, temporal, and parietal hypoperfusion. The long term treatment consisted of a low protein diet, oral sodium phenylbutyrate, and supplementation with L-carnitine and citrulline.
Table 1 summarises the patient's neuropsychological performances. We noted reduced spontaneous language, a deficit in naming, ${ }^{3}$ and poor verbal fluency. ${ }^{4}$ She showed perplexity with respect to the meaning of common words. We qualified this picture as "a massive lexical deficiency"; her performance also suggested the presence of a defect in semantic memory. There was no visual agnosia. ${ }^{5}$ Category matching and functional matching were deficient. ${ }^{7}$ When she had to attribute the specific category common to four objects, only two of 15 categories were correctly identified. She had great difficulty in an "object decision" test. ${ }^{5}$ In auditory tests, which solicit semantic memory and mental imagery, she produced only incomplete definitions, essentially of the functional type (for example, a wallet: "to put money in"), or indeed of the categorical type (for example, an elephant: "it's an animal"). She was unable to find a specific visual characteristic, such as colour (grey for elephant), or other specificity (the trunk of the elephant), and sometimes suggested aberrant definitions. Drawings of these same items made from memory were reduced to representations that were non-specific or erroneous. However, the copied picture ${ }^{5}$ was normal, suggesting no constructive apraxia. She had great difficulty in mentally comparing two similar objects to isolate the specific characteristic differentiating them (for example, the stripes of a tiger/the spots of a leopard) or to designate the characteristic properties of objects named by the examiner (for example, the colours and their orientation in the French flag, the shape of Mickey Mouse's ears).

Her writing presented purely graphic difficulties and numerous dysorthographic errors, which were unrelated to her premorbid level (high school baccalaureate). These errors suggested that even the orthographic representation of words stored in her memory were no longer easily available.

Overall memory capacity was globally impaired and mainly concerned retrograde memory. She no longer remembered that she had passed her baccalaureate, had begun studies in social work, and as would be expected, had no recollection of her present study curriculum. Her gap in retrograde memory went back to adolescence. Anterograde memory was also very disturbed. However, with regard to a film that she had seen a few weeks earlier, she had memorised all the information relating to the source of the event, but not longer had access to specific semantic information concerning the story. Didactic knowledge was impaired. ${ }^{8}$ Her description of the Eiffel Tower was limited to the following definition: "It's in Paris, it's big on top and small on bottom". She was unable to offer information about famous names-for example, the Mona Lisa or Agatha Christie (the last mentioned was her favourite author before her illness). She could not say when the Second World War began and did not understand the importance of the concept of the alphabet. Transitory verbal and visual memory ${ }^{8}$ were pathological, but working memory

Abbreviation: OCTD, ornithine transcarbamylase deficiency 


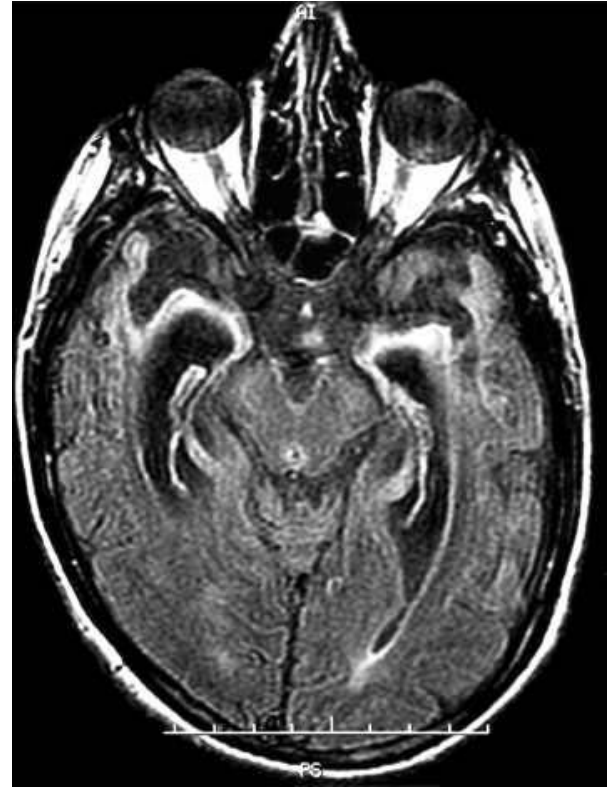

Figure 1 Axial fluid attenuated inversion recovery magnetic resonance imaging scan showing extensive bilateral anterior temporal atrophy, high signal intensity in the temporal cortex at the level of the uncus, and dilatation of the temporal horns.

was correct. ${ }^{8}$ Nevertheless, she remained well oriented in time.

Despite six months of intensive speech therapy she has remained very handicapped in her daily life and has been incapable of resuming her studies. Nevertheless, she has reconstructed a few autobiographical memories thanks to family photo albums and memory relearning with the help of her immediate family.

\section{DISCUSSION}

OTCD is a transmitted X linked deficiency in which late onset forms have been described in both men and women. ${ }^{1}$ During the first years of life, the clinical presentation can be variable, ranging from a simple distaste for protein to psychiatric disorders or coma with raised serum ammonia. The neurological manifestations in infants and children are mainly mental retardation, hypotonia, convulsions, mental confusion, and headache, ${ }^{9}$ but such neurological symptoms may occur in heterozygous adult females, as in the case of our patient. The neuropsychological consequences of OTCD have received little attention, and most often remain limited to a low intellectual quotient (IQ) in children or adolescents. ${ }^{10}{ }^{11}$ According to Maestri et al, ${ }^{12}$ the intellectual outcome is poor in $20-40 \%$ of patients. Msall and colleagues ${ }^{13}$ confirmed these data. In a survey of the long term cognitive and neuropsychological outcomes in children treated for OTCD, Nicolaides et al described either global cognitive impairment or learning difficulties, including deficits in executive functions. ${ }^{11}$

After recovery from the coma and with a decrease in serum ammonia, our patient developed severe anterograde and retrograde memory loss and distinctive language disorders characterised by a loss of the meaning of words, related to a semantic impairment. Semantic memory regroups each individual's general knowledge, independent of the spatial and temporal context in which they were acquired, in addition to their personal history. Thus, it defines the knowledge and culture of an individual, and constitutes the didactic memory. ${ }^{14}$ An impairment in semantic memory can be explained by a deficiency in semantic representations or damage to the semantic stock itself, but is not easy to test. ${ }^{15}$

This semantic deficit is not easy to explain. We reported anterior temporal atrophy, high signal intensity at the level of the uncus and along the insular cortex, and a severe frontal, temporal, and parietal hypoperfusion on SPECT. Our findings on imagery are consistent with Kurihara et al, ${ }^{16}$ who described cortical abnormalities, particularly in the cingulated gyrus

Table 1 Neuropsychological performance

\begin{tabular}{|c|c|}
\hline & Scores and comments \\
\hline \multicolumn{2}{|l|}{ Language } \\
\hline Naming (DO 80) ${ }^{3}$ & $51 / 80(-28 \mathrm{SD})$ numerous anomic type errors \\
\hline \multicolumn{2}{|l|}{ Verbal fluency ${ }^{4}$} \\
\hline Lexical fluency (in 1 minute) & $8(-2.9 \mathrm{SD})$ \\
\hline Formal fluency (in 1 minute) & $7(-1.8 \mathrm{SD})$ \\
\hline \multicolumn{2}{|l|}{ Visual perception } \\
\hline \multicolumn{2}{|l|}{ Visual matching ${ }^{5}$} \\
\hline Of two examples of the same object & $32 / 32$ \\
\hline Of two views of the same object & $22 / 25$ (-0.6 SD, not pathological) \\
\hline Functional and category matching & $11 / 50$ (pathological score $<47 / 50$ ) \\
\hline \multicolumn{2}{|l|}{ Semantic tests } \\
\hline Specific category common to 4 objects (personal test) & $2 / 15$ categories \\
\hline Object decision test $t^{5}$ & $\begin{array}{l}\text { Real objects, } 12 / 25 \text { accepted; non objects, 16/25 } \\
\text { accepted as real objects }\end{array}$ \\
\hline Object decision (forced choice) ${ }^{6}$ & $11 / 50$ \\
\hline \multicolumn{2}{|l|}{ Mental imagery } \\
\hline $\begin{array}{l}\text { Drawing from memory } \\
\text { Auditory tests which solicit semantic memory and } \\
\text { mental imagery (personal test) }\end{array}$ & $\begin{array}{l}\text { Only non-specific or erroneous representations } \\
\text { Incomplete definition (functional type) Impossible to } \\
\text { find an additional visual characteristic }\end{array}$ \\
\hline $\begin{array}{l}\text { Mentally comparing two similar objects (personal } \\
\text { test) }\end{array}$ & Impairment \\
\hline \multicolumn{2}{|l|}{ Memory ${ }^{8}$} \\
\hline Global memory score & 62 \\
\hline Subtest orientation & $5 / 5$ \\
\hline Subtest information (didactic knowledge) & $0 / 18$ \\
\hline Direct span & 8 \\
\hline Indirect span & 8 \\
\hline Writing & $\begin{array}{l}\text { Graphic difficulties (telescoping, distortion of figures, } \\
\text { numerous erasures and crossing out) } \\
\text { Dysorthographic errors }\end{array}$ \\
\hline
\end{tabular}


and insular cortex. Anatomically, the temporal lobe, particularly the inferior lateral portion of the left temporal cortex, plays an important role in semantic memory. ${ }^{17}$ Imagery studies generally show bilateral temporal atrophy, which sometimes predominates on the left side and often involves the inferior lateral portion. ${ }^{18}$ Semantic disorders can be the result of Alzheimer's disease, ${ }^{19}$ semantic dementia, ${ }^{20}$ or herpes encephalitis. ${ }^{18}$ To our knowledge, no descriptions of a semantic disorder associated with a metabolic disorder have been reported. Our case study illustrates that OTCD can first become apparent in adulthood. The neuropsychological disorders can be quite unusual and difficult to diagnose when appropriate tools for evaluation are not available. A semantic disorder can be confused with a simple language disorder, and should be considered in a subject who "looses" general knowledge or who manifests a reduction in fluency. The pathophysiological mechanism of cerebral nervous system injury in OTCD is unclear. A role for the intracerebral accumulation of glutamine has been suggested, ${ }^{1}$ with consequences including changes in intracellular osmolarity, damage to astrocytes, brain oedema, and cerebral hypoperfusion.

Our observation suggests that a precise neuropsychological investigation should be carried out in any adult with OTCD, whether the deficiency was first discovered in childhood or in adulthood, as in our patient, so that their treatment can be best tailored to their rehabilitation. At the moment, it is difficult to determine whether urea cycle disorders produce a distinct neuropsychological profile. To determine whether OTCD induces semantic-type disorders, suggesting temporal lobe dysfunction (left inferior lateral portion), or a more heterogeneous picture, suggesting multiple dysfunction, it would be instructive to evaluate the neuropsychological profile of other adult cases.

\section{Authors' affiliations \\ S Rimbaux, C Hommet, D Perrier, A Autret, Service de Neurologie, Hôpital Bretonneau, 37044 Tours, cedex, France \\ C Hommet, Inserm U 316, 37044 Tours, Cedex, France \\ J P Cottier, Service de Neuroradiologie, Hôpital Bretonneau \\ A Legras, Service de Réanimation Médicale, Hôpital Bretonneau F Labarthe, Service de Pédiatrie, R Hôpital Clocheville, 37044 Tours, cedex France \\ L Lemarcis, F Maillot, Service de Médecine Interne A, Hôpital Bretonneau \\ Conflicting interests: none declared}

Correspondence to: $\operatorname{Dr} \mathrm{C}$ Hommet, Service de Neurologie, Hôpital Bretonneau, 37044 Tours, Cedex, France; hommet@med.univ-tours.fr
Received 1 September 2003

In revised form 28 November 2003

Accepted 11 November 2003

\section{REFERENCES}

1 Brusilow SW, Horwich AL. Urea cycle enzymes. In: Scriver CR, Beaudet AL Sly WS, et al, eds. The metabolic and molecular bases of inherited disease, 8th ed. New York: McGraw-Hill, 2001:1909-63.

2 Legras A, Labarthe F, Maillot F, et al. Late diagnosis of ornithine transcarbamylase defect in three related female patients: polymorphic presentations. Crit Care Med 2002;30/1:241-4

3 Metz-lutz MN, Perrier D, Puchard B, et al. Standardisation d'un test de dénomination orale: contrôle des effets de l'âge, du sexe et du niveau de scolarité chez des sujets adultes normaux. Rev Neuropsychol 1991; 1:73-95.

4 Cardebat D, Doyon B, Puel M, et al. Evocation lexicale formelle et sémantique chez des sujets normaux. Performances et dynamiques de production en fonction du sexe, de l'âge et du niveau d'étude. Acta Neurol Belg 1990;90:207-17.

5 Riddoch HJ, Humphreys GW. Birmingham object recognition battery (BORB). Hove, UK: Laurence Erlbaum Associates, Publishers, 1993.

6 Kremin H, Dubois B, Michon A, et al. A propos de l'inefficacité du paradigme standard de "désignation verbale" pour juger de la préservation de la reconnaissance et compréhension d'images chez des sujets atteints de maladies dégénératives. In: Nargeot MC, Ritchie K, Touchon J, eds. Actualités 1998 sur la maladie d'Alzheimer et les syndromes apparentés. Marseille: Solal, 1998:437-43.

7 Howard D, Patterson K. The pyramids and palm trees test: a test of semantic access from words and pictures. Bury St Edmonds: Thames Valley Test Company, 1992.

8 Wechsler D. Wechsler Memory Scale revised. San Antonio TE: Psychological Corporation, 1987

9 Butterworth RF. Evidence for forebrain cholinergic neuronal loss in congenital ornithine transcarbamylase deficiency. Metab Brain Dis 2000;15/1:83-91.

10 D'Hooge R, Marescau B, Qureshi IA, et al. Impaired cognitive performance in ornithine transcarbamylase-deficient mice on arginine-free diet. Brain Res 2000;876: 1-9.

11 Nicolaides P, Liebsch D, Dale N, et al. Neurological outcome of patients with ornithine carbamoyltranferase deficiency. Arch Dis Child 2002;86:54-6.

12 Maestri NE, Brusilow SW, Clissord DB, et al. Long-term treatment of girls with ornithine transcarbamylase deficiency. N Engl J Med 1996;335:855-9.

13 Msall M, Batshaw ML, Suss R, et al. Neurologic outcome in children with inborn errors of urea synthesis. N Engl J Med 1984;310:1500-5.

14 Patterson K, Hodges JR. Disorders of semantic memory. In: Baddeley AD, Wilson BA, Watts FN, eds. Handbook of memory disorders. Chichester, UK: John Wiley, 1995:167-86.

15 Van Der Linden M, Meulemans T, Belleville $S$, et al. L'évaluation des troubles de la mémoire. In: Seron X, Van Der Linden M, eds. Traité de neuropsychologie clinique. Marseille: Solal, 2000:115-55.

16 Kurihara A, Takanashi J, Tomita M, et al. Magnetic resonance imaging in late onset ornithine transcarbamylase deficiency. Brain Dev 2003;2:40-4

17 Papps BP, Best JJK, O'Carroll RE. Semantic memory functioning and the left temporal lobe. Neurocase 2000;6:179-92.

18 Dussaux P, Brion F, Plas J, et al. Lésions extra-hippocampiques et altération des connaissances didactiques (mémoire explicite sémantique). Rev Neurol 1998;154/10:675-80.

19 Chertkow H, Bub D. Semantic memory loss in dementia of Alzheimer's type. Brain 1990;113:397-417.

20 Snowden JS, Goulding PJ, Neary D. Semantic dementia: a form of circumscribed cerebral atrophy. Behav Neurol 1989;2:167-82. 